\title{
MEWUJUDKAN SOCIOPRENEUR DALAM ERA REVOLUSI INDUSTRI 4.0
}

\author{
${ }^{1 *}$ Ahmad Nurhadi, ${ }^{2}$ Mahnun Mas'adi, ${ }^{3}$ Heri Murtiyoko, ${ }^{4}$ Aden Prawiro \\ Sudarso, ${ }^{5}$ Widhi Wicaksono \\ Universitas Pamulang, Tangerang Selatan, Indonesia \\ Email : $\underline{\text { dosen01023@unpam.ac.id }}$
}

\begin{abstract}
Manuskrip: Desember -2021; Ditinjau: Desember -2021; Diterima: Desember -2021; Online: Januari-2022; Diterbitkan: Januari-2022
\end{abstract}

\begin{abstract}
ABSTRAK
Pada dasarnya, tujuan utama sebuah bisnis adalah memperoleh keuntungan yang maksimal, namun jika bisnis dapat membantu dari sisi sosial, maka usaha tersebut lebih banyak diharapkan oleh masyarakat, seperti sociopreneur atau sociopreneurship yaitu menggabungkan konsep bisnis yang biasanya bertujuan memperoleh laba dengan isu sosial yang bertujuan membantu masyarakat sekitar, baik dari sisi tenaga kerja yang kita pekerjakan orang-orang yang kurang mampu atau difabel, ataupun juga bahan baku yang dibeli berasal dari usaha-usaha masyarakat di sekitar sebagai bentuk sosial dan kepedulian kita kepada masyarakat. Adapun tujuan dari Pengabdian kepada Masyarakat (PKM) ini adalah untuk memotivasi mengenai ilmu kewirausahaan dan motivasi kisah sukses dalam berwirausaha, terutama materi yang berkaitan dengan Sociopreneur terhadap anggota TWT Learning Centre. Metode yang digunakan pada Pengabdian masyarakat ini berupa penyampaian materi secara verbal melalui media zoom mengenai tantangan wirausaha di era revolusi industri 4.0, sudah sepatutnya sebuah Usaha Mikro Kecil Menengah (UMKM) memiliki kemampuan mengikuti perkembangan teknologi yang ada agar sebuah bisnis tersebut dapat menjaga eksistensinya dan bersaing dengan pesaing bisnis lainnya. Hasil pengabdian masyarakat oleh Tim PKM Dosen Universitas Pamulang dapat membuahkan hasil yang positif terlihat dari antusias dan bersemangat dalam mengikuti pelaksanaan PKM dari awal hingga akhir, baik saat penyampaian materi, maupun sesi tanya jawab dan diskusi, serta bertambahnya ilmu pengetahuan, wawasan dan bimbingan mengenai materi yang berkaitan dengan motivasi menjadi seorang Sociopreneur di era revolusi industri 4.0.
\end{abstract}

\section{Kata Kunci: Sociopreneur, TWT Learning Centre, Revolusi Industri 4.0}

\section{PENDAHULUAN}

Di Era Revolusi Industri 4.0 sebuah UMKM (Usaha Mikro Kecil Menengah) harus dapat menghadapi tantangan untuk bertahan dan berkembang pada era modern dan penerapan teknologi digital, dimana UMKM saat ini dituntut untuk 
dapat beradaptasi dengan teknologi untuk bersaing dengan pesaing usaha sejenis lainnya.

Pada dasaranya, salah satu tujuan utama sebuah usaha adalah memperoleh keuntungan yang maksimal, namun jika usaha dapat membantu dari sisi sosial, maka usaha tersebut lebih banyak diharapkan oleh masyarakat, seperti sociopreneur atau sociopreneurship yaitu menggabungkan konsep bisnis yang biasanya bertujuan memperoleh laba dengan isu sosial yang bertujuan membantu masyarakat atau menolong orang lain, baik dari sisi tenaga kerja yang kita pekerjakan orang-orang yang kurang mampu atau difabel, ataupun juga bahan baku yang dibeli berasal dari usaha-usaha masyarakat di sekitar sebagai bentuk sosial dan kepedulian kita kepada masyarakat.

Oleh karena itu, sociopreneur sebagai salah satu jenis pelaku usaha yang perlu didukung agar semakin bertambah jumlah pelaku usaha yang dapat berkontribusi menurunkan angka pengangguran, sebagaimana menurut Direktur Pengembangan Pasar Ditjen Binapenta \& PKK Kementerian Ketenagakerjaan (Kemenaker) Republik Indonesia (RI), Roositiawati dalam Amalia, 2019. "Angka pengangguran selama lima tahun terahir tercatat mengalami penurunan di mana kontribusi terbesar dari penurunan pengangguran berasal dari tumbuhnya socio-enterprise di Indonesia, yaitu angka pengangguran mengalami penurunan menjadi 5,3\% atau 6,8 juta selama lima tahun terakhir. Bahkan angkatan kerja Indonesia sudah mencapai 131 juta yang didominasi oleh kaum muda. Kita mampu turunkan angka pengangguran, itu berarti bahwa tidak hanya sektor formal yang bergerak untuk menyerap tenaga kerja tetapi juga tumbuhnya entrepreneur dan socio-preneur," (www.beritasatu.com).

Adapun gambaran perkembangannya penulis sajikan dalam bentuk diagram, sebagai berikut:

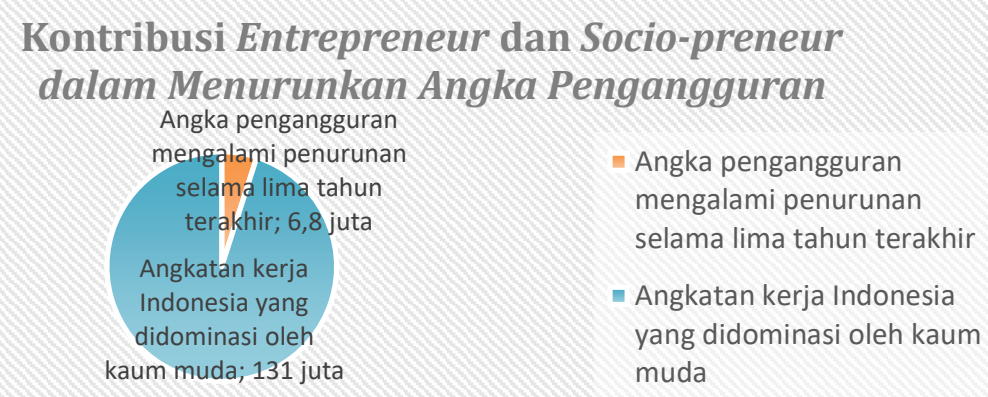

Gambar 1. Kontribusi Socio-preneur dalam Menurunkan Angka Pengangguran

Dalam mewujudkan Sociopreneur, maka kita perlu juga beradaptasi dengan perkembangan zaman terutama di era revolusi industri 4.0, di mana banyak perusahaan, seperti dalam bidang transportasi online yaitu Go-Jek dan Grab, mereka mampu beradaptasi dengan teknologi informasi, sehingga eksistensi keberadaannya terus berkembang di era globalisasi saat ini.

Dalam Sangaji, N., et. al., (2019). "Di Era revolusi industri 4.0 transportasi yang bersifat konvensional tidak pernah diprediksi bahwa model ini transportasi 
konvensional ini yang dahulu banyak digunakan oleh masyarakat untuk kepentingan mobilitas manusia, namun pada era revolusi industri 4.0 model transportasi konvensional ini sudah sedikit digunakan oleh masyarakat, dimana dapat terlihat antara taksi konvensional versi taksi online atau ojek pangkalan dengan ojek online."

Persaingan usaha dalam dalam Revolusi Industri 4.0 saat ini, seperti halnya mewujudkan sociopreneur di tengah masyarakat, maka perlu adanya yang mendukung dan membantu untuk mewujudkannya, sepertinya halnya TWT Learning Centre sebagai Lembaga Pelatihan, Konsultan Bisnis dan Pendidikan untuk membantu masyarakat terutama generasi milineal agar dapat memiliki sebuah bisnis terutama menjadi seorang sociopreneur.

Namun di era revolusi industri UMKM harus dapat bertahan karena banyak di antara UMKM belum memaksimalkan untuk menggunakan teknologi digital, seperti pemasaran via online demi bersaing di tengah Revolusi Industri 4.0 seperti saat ini.

Hal tersebut diperkuat juga dalam sebuah riset oleh A. Budiyanto, \& A.A. Effendy, (2020), diantara hambatan perkembangan UMKM ialah "Terbatasnya sarana dan prasarana usaha terutama berhubungan dengan alat-alat teknologi. Kebanyakan UMKM menggunakan teknologi yang masih sederhana sehingga sulit untuk bersaing secara kualitas dan kuantitas."

Karena saat ini masanya revolusi Industri 4.0, bahkan sudah memasuki ke area Society 5.0., dimana komponen utamanya adalah manusia yang dapat menciptakan nilai baru melalui perkembangan teknologi, termasuk dalam hal pemasaran melalui digital atau online dalam persaiangan usaha, hal ini sebagaimana riset yang dilakukan oleh Effendy, A. A., \& Sunarsi, D. (2020). "Promosi Online lebih efektif pemasarannya melalui media sosial, dibandingkan promosi melalui media elektronik, dan media cetak."

Oleh karena itu, TWT Learning Centre sebagai Lembaga Pelatihan, Konsultan Bisnis dan Pendidikan yang membantu masyarakat terutama generasi milineal agar dapat memiliki sebuah bisnis terutama menjadi seorang sociopreneur, khususnya Kota Tangerang Selatan, perlu mempelajari keilmuan berbisnis, agar bisnis dapat bersaing di Revolusi Industri 4.0 seperti saat ini. Namun para generasi muda yang mengikuti pelatihan melalui TWT Learning Centre perlu juga disupport. "Sebuah lembaga, semestinya perlu didukung oleh semua eleman masyarakat, baik guru, orangtua, masyarakat sekitar dan termasuk dosen-dosen diharapkan dapat mengabdi dan berperan serta dalam membentuk untuk mewujudkannya. (Effendy, A. A., et. al., 2020).

Dalam pengabdian kepada masyarakat (PKM) yang dilakukan oleh dosendosen UNPAM khsusnya dosen Manajemen Fakultas Ekonomi dan Bisnis, merupakan salah satu upaya dalam berpartisipasi untuk memberikan bekal dan ilmu pengetahuan, wawasan dan praktek berwirausaha yang tergabung dalam Lembaga Pendidikan, TWT Learning Centre dengan tema, "Mewujudkan Sociopreneur dalam Era Revolusi Industri 4.0”. 


\section{METODE}

Metode Pelaksanaan Pengabdian Masyarakat ini di antaranya : Tahap Pertama yaitu sambutan dari ketua LPPM (Lembaga Penelitian dan Pengabdian kepada Masyarakat) Universitas Pamulang, Bapak Dr. Ali Maddinsyah, S.E., M.M. dan sambutan dari Mitra PKM yaitu Bapak Iskandar Z. Sitanggang, S.E. sebagai Pimpinan TWT Learning Centre, seperti gambar terlamnir:

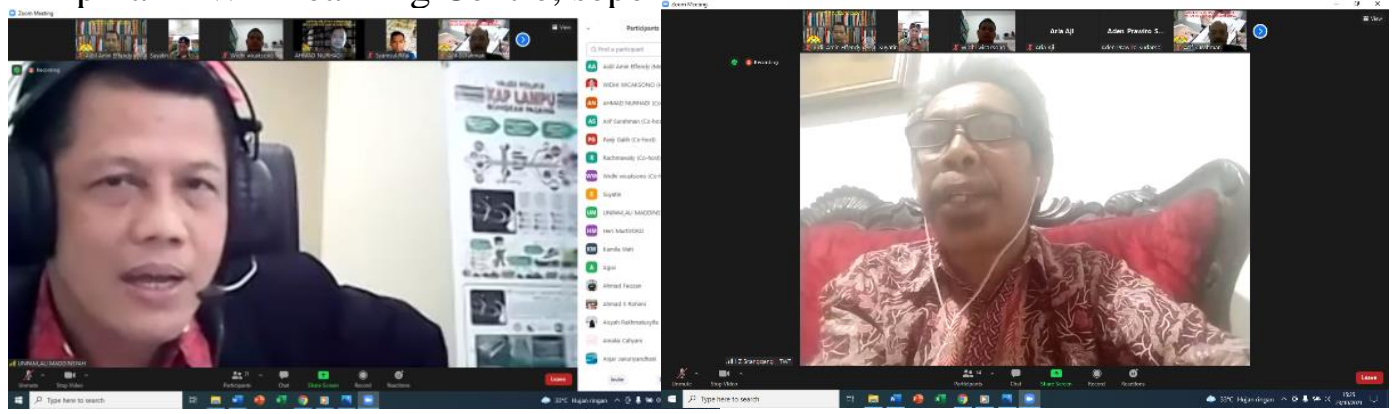

Gambar 2. Sambutan dari ketua LPPM Unpam dan Mitra PKM

Tahap Kedua yaitu Pemberian materi PKM kepada TWT Learning Centre dan peserta PKM dari kota lainnya, di antara materi yang disampaikan Tim PKM Dosen yaitu mengenai materi yang berkaitan dengan motivasi menjadi Sociopreneur di era revolusi industri 4.0. Sebagaimana Effendy, A. A., et al. (2020), menurut Prof. Dr. S. Nasution (2015:26) berpendapat mengenai "Ciri-ciri Belajar yang ditinjau berdasarkan sumber yaitu diantaranya memanfaatkan sepenuhnya segala sumber informasi sebagai sumber bagi pelajaran termasuk alat-alat audiovisual dan memberi kesempatan untuk merencanakan kegiatan belajar dengan mempertimbangkan sumber-sumber yang tersedia."

Dalam pemberian materi PKM oleh dosen-dosen menggunakan alat bantu berupa aplikasi zoom dikarenakan masih dalam masa pandemi, seperti gambar di bawah ini;
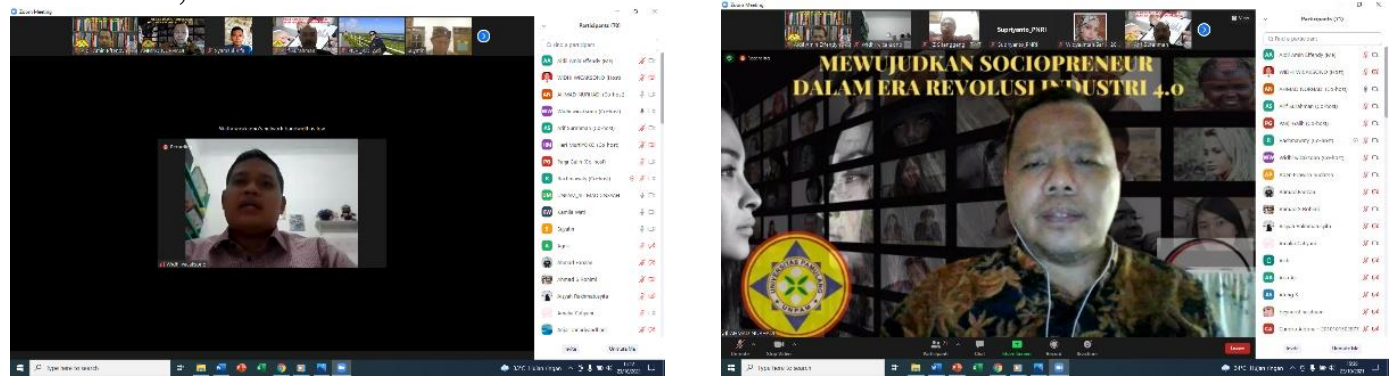

Gambar 3. Tim PKM Membuka Kegiatan dan Menyampaikan Materi Pengabdian

Tim PKM Dosen diwakili Bapak Widhi Wicaksono, S.E., M.M. membuka kegiatan pengabdian dan dilanjutkan oleh Bapak Ahmad Nurhadi, S.E., M.M. sebagai narasumber PKM yang menyampaikan materi mengenai menjadi seorang Sociopreneur di era revolusi industri 4.0. Tim PKM dosen lainnya, Bapak Aden Prawiro Sudarso, S.E., M.M. dan Bapak Mahnun Mas'adi, S.E., M.M. yang turut berpartisipasi mensukseskan kegiatan pengabdian ini. 
Tahap ketiga yang merupakan tahapan terakhir dalam sesi pengabdian ini yaitu: Diskusi dan Tanya Jawab mengenai menjadi Sociopreneur di era revolusi industri 4.0. Salah satu cara terbaik menjadi Sociopreneur yaitu dengan berusaha menggabungkan konsep bisnis yang biasanya bertujuan memperoleh laba dengan isu sosial yang bertujuan membantu masyarakat untuk menjadi seorang Sociopreneur, di antaranya melalui sebuah motivasi yang diberikan berupa kisah Sukses dalam berwirausaha untuk menjadi seorang Sociopreneur. Kegiatan diadakan pada TWT Learning Centre selama 3 hari yaitu pada tanggal 23-25 Oktober 2021 melalui Video Conference dengan aplikasi Zoom.

\section{HASIL DAN PEMBAHASAN}

Hasil dari pemberian materi mengenai cara menjadi sociopreneur di era revolusi industri 4.0 oleh dosen Manajemen Universitas Pamulang dan simulasi cara menjadi sociopreneur di era revolusi industri agar peserta PKM dapat berhasil menerapkannya.

Setelah Tim PKM Dosen menyampaikan materi PKM, dilanjutkan dengan sesi tanya jawab kepada peserta agar peserta dapat lebih memahami dan menerapkan keilmuan materi PKM ini dalam usahnya masing-masing. Hasil pengabdian masyarakat yang diperoleh adalah bertambahnya keilmuan TWT Learning Centre, khususnya dalam mewujudkan menjadi sociopreneur di era revolusi industri;
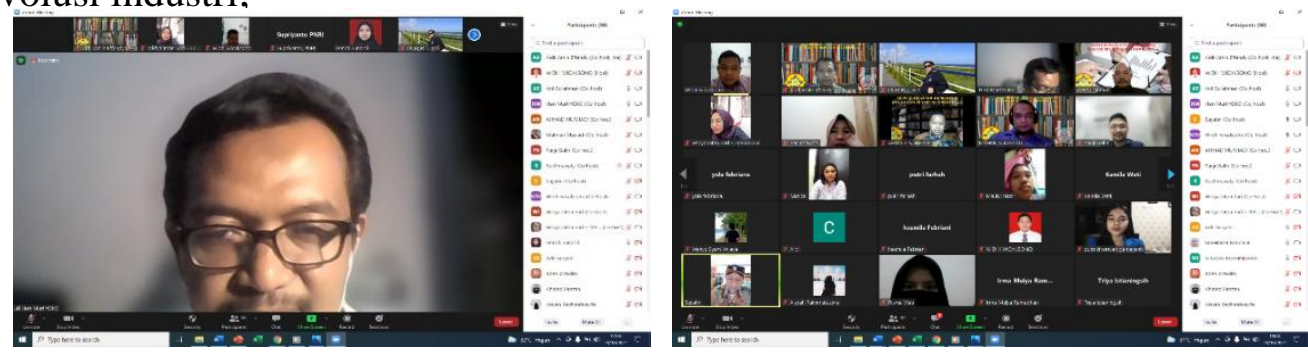

Gambar 4. Sesi Diskusi dan Tanya Jawab bersama TWT Learning Centre

Adapun gambar di atas yaitu diskusi dan tanya jawab yang dipimpin oleh Bapak Heri Murtiyoko, S.Pd., M.M. bersama para peserta PKM dari TWT Learning Centre. Dalam proses berlangsungnya tanya jawab, Tim PKM yang merupakan dosen-dosen Unpam menanggapi dan menjawab pertanyaan yang diajukan oleh para peserta dan memberikan hadiah kepada para peserta yang bertanya dan berhasil menjawab pertanyaan dari Tim PKM Dosen Universitas Pamulang.

\section{KESIMPULAN}

Hasil dari Pelaksanaan kegiatan PKM oleh dosen-dosen Fakultas Ekonomi dan Bisnis Universitas Pamulang dapat membuahkan hasil yang positif terlihat dari antusias dan bersemangat dalam mengikuti pemberian materi, tanya jawab dan kuis.

Saran kami bagi TWT Learning Centre untuk dapat secara konsisten berusaha menerapkan konsep bisnis yang bertujuan memperoleh laba diiringi dengan nilai sosial yang bertujuan membantu masyarakat untuk menjadi seorang Sociopreneur. 
Kami berharap kegiatan pengabdian kepada masyarakat di masa yang akan datang dapat lebih terprogram dan terlaksana dengan baik. Semoga kegiatan pengabdian masyarakat ini dapat bermanfaat bagi masyarakat, khususnya TWT Learning Centre.

\section{DAFTAR PUSTAKA}

Amalia, Happy Amanda. 2019. "Pertumbuhan Socio-preneur Turunkan Angka Pengangguran", https://www.beritasatu.com/nasional/539817/pertumbuhansociopreneur-turunkan-angka-pengangguran, diakses pada 15 Oktober 2021

Budiyanto, A., \& Effendy, A. A. (2020). Analisa Kebijakan Pemerintah Kota Tangerang Selatan terhadap Pemberdayaan Koperasi dan UMKM dan Dampaknya terhadap Pemerataan Kesejahteraan Masyarakat. Jurnal Mandiri: Ilmu Pengetahuan, Seni, Dan Teknologi, 4(1), 80-93.

Effendy, A. A., Budiyanto, A., Nurhadi, A., Murtiyoko, H., \& Mas'adi, M. (2020). "Implementasi Kewirausahaan dan Koperasi di Sekolah pada SMK Mulia Buana, Parung Panjang-Kab. Bogor." DEDIKASI PKM, 1(2), 105-110.

Effendy, A. A., Mas'adi, M., Wicaksono, W., Nurhadi, A., \& Murtiyoko, H. (2020). "Mewujudkan Generasi Muda Yang Unggul Di Era Globalisasi Dengan Berbekal Ilmu Wirausaha Yang Kreatif, Inovatif Dan Diferensiatif Pada Remaja Masjid Al Hikmah Reni Jaya Pamulang Tangerang Selatan. ” Jurnal Pengabdian Dharma Laksana, 3(1), 8-15.

Effendy, A. A., et al. (2020). "Peningkatan Profesionalisme Guru Dan Pengembangan SDM Dalam Menghadapi Era Revolusi Industri 4.0 Pada Guru Smk Mulia Buana Parung Panjang Bogor.” Abdi Laksana, 1(2).

Effendy, A. A., \& Sunarsi, D. (2020). Persepsi Mahasiswa Terhadap Kemampuan Dalam Mendirikan UMKM Dan Efektivitas Promosi Melalui Online Di Kota Tangerang Selatan. Jurnal Ilmiah MEA (Manajemen, Ekonomi, \& Akuntansi), 4(3), 702-714.

Haryadi, R. N., et al. (2021). Sosialisasi Penggunaan Online Shop berbasis Website di UMKM Cimanggis. Jurnal Pengabdian Masyarakat Madani (JPMM), 1(1), 10-16. https://doi.org/10.51805/jpmm.v1i1.3

Mas'adi, M., Effendy, A. A., Nurhadi, A., Wicaksono, W., \& Murtiyoko, H. (2021). Berwirausaha Dengan Semangat Kolaborasi Bersama Kurir Online Pada Pelaku UMKM Di Wilayah Reni Jaya Pamulang Barat. Jurnal Pengabdian Dharma Laksana, 3(2), 173-178.

Nasution, Prof. Dr. S., (2015). "Berbagai Pendekatan dalam Proses Belajar dan Mengajar”, PT Bumi Aksara, Jakarta

Sangaji, N., Wiyono, V. H., \& Mulyaningsih, T. (2019). Pengaruh Revolusi Industri 4.0 pada Kewirausahaan untuk Kemandirian Ekonomi. Prosiding Seminar Bisnis Magister Manajemen (SAMBIS) 2019.

Sunarsi, D., \& Asmalah, L. (2018). "Pelatihan Manajemen Pengembangan Diri Bagi Penerima Beasiswa RZIS UGM Dan Dompet Shalahuddin Jogjakarta". Jurnal Pengabdian Dharma Laksana, 1(1). 